\title{
Aprofundar o Método de François Delsarte: As atitudes das pernas
}

\author{
Franck Waille \\ Laboratório de Pesquisa Histórica Rhône-Alpes (LARHRA), França \\ E-mail: franck.cw@gmail.com
}

Resumo

A reconstrução dos ensinamentos práticos (para o corpo, e mais ainda a voz) de François Delsarte levanta um verdadeiro desafio metodológico: se esses ensinamentos desempenharam um papel determinante no surgimento da modernidade das artes cênicas, práticas psicossomáticas e educação somática, eles foram essencialmente transmitidos "oralmente" de mestre para aluno. E eles foram, por um lado, perdidos. É a partir dos elementos de transmissão textual, associados a uma prática da dança moderna, do teatro e de abordagens somáticas, que é possível encontrar um entendimento o mais próximo possível de suas versões originais, sem ter a pretensão de poder voltar a esses. Ainda mais que as numerosas nuanças que Delsarte introduziu em seu ensino convidam a uma dinâmica aberta: não procurar "a letra" mas "o espírito" de seu trabalho, numa perspectiva de constante renovação. Essa abordagem é a da pesquisa de Franck Waille, que tem sido constantemente aperfeiçoada desde o início dos anos 2000. Ela diz respeito a diferentes elementos do expressivo método somático de Delsarte. Este artigo apresenta uma atualização sobre as atitudes das pernas, favorecida pelo encontro com a pesquisa de Clóvis Massa sobre Delsarte feita no início dos anos 1990.

Palavras-chave

François Delsarte. Atitudes / Acorde de nona. Expressão de pernas. Artes cênicas. Educação somática.
Abstract

The reconstruction of the practical teachings (for the body, and even more the voice) of François Delsarte raises a real methodological challenge: if these teachings played a determining role in the emergence of the modernity of the performing arts, practices psychosomatic and somatic education, they were essentially transmitted "in an oral way" from master to student. And they were, for one, lost. It is from the elements of textual transmission, associated with a practice of modern dance, drama and somatic approaches, that it is possible to find an understanding as close as possible to their original versions, without pretending to be able to return to these. Especially since the many nuances that Delsarte introduced into his teaching invite an open dynamic: not looking for "the letter" but "the spirit" of his work, in a perspective of constant renewal. This approach is that of the research of Franck Waille, which has been constantly refined since the beginning of the 2000s. It concerns different elements of Delsarte's Expressive Somatic Method. This article presents an update on the attitudes of the legs, favored by the meeting with the research of Clóvis Massa on Delsarte made in the early 1990s.

Keywords

François Delsarte. Attitudes / Ninth Agreement. Expression of the legs. Scenic arts. Somatic education. 


\section{Introdução}

Os ensinamentos expressivos de François Delsarte (1811-1871), que desempenharam um papel importante no surgimento das artes modernas no Ocidente desde o final do século XIX, beneficiam desde os anos 1970 de uma série de estudos e publicações (universitárias, mas não apenas) permitindo entender melhor o conteúdo e a riqueza deles. Minha própria pesquisa faz parte dessa dinâmica e está em constante renovação. Desse modo, meu livro O método somático expressivo François Delsarte (2016) mostrou um aprofundamento de alguns aspectos da minha tese, Corps, artes e espiritualidade em François Delsarte (18111871) (2009), particularmente em relação ao trabalho do torso e a compreensão prática das atitudes das pernas, chamadas também "atitudes de base" (CABLE, s.d., p. 1).

Dois períodos favoreceram a continuidade do aprofundamento de minha pesquisa referente a Delsarte. O pós-doutorado feito no Departamento de Dança da Universidade do Quebec em Montreal (UQAM) em 2014 e 2015 me permitiu seguir a exploração dos manuscritos em torno do trabalho do torso. E foi durante um segundo pós-doutorado no Departamento de Educação da Universidade Federal do Rio Grande do Sul (UFRGS) em 2016 e 2017 que pude rever parte da abordagem de trabalho das atitudes das pernas. Isto foi favorecido pelo encontro com o trabalho de Clóvis Massa feito em Delsarte no início dos anos 90. É o resultado deste duplo aprofundamento que apresento aqui.

Para o torso, eu me distanciei das informações fornecidas pela delsartista americana Genevieve Stebbins (1977), as quais, se elas tem a imensa vantagem de uma grande cla- reza (lições muito organizadas e detalhadas), apresentam desvios em relação aos manuscritos mais próximos dos ensinamentos originais de Delsarte. Eu também revisitei parcialmente o estudo das atitudes das pernas, relendo os manuscritos.

O trabalho das pernas e do torso cai dentro da estrutura mais geral do trabalho expressivo de diferentes partes do corpo com a ferramenta delsartiana chamada de nono acorde. Esta ferramenta tem sido a fonte de muitas ambiguidades na transmissão e recepção dos ensinamentos de Delsarte. Então, a princípio, apresentarei uma síntese sobre o nono acorde, para entender a dinâmica. Em um segundo momento, vou expor textos e fotografias das contribuições combinadas de minhas pesquisas e as de Clóvis Massa sobre as atitudes das pernas. Por fim, num terceiro momento (que será objeto de um artigo à parte ${ }^{1}$ ), retornarei às atitudes do torso (com textos e imagens também) e ampliarei minha apresentação com uma reflexão sobre a noção de equilíbrio harmônico característico das transmissões delsartianas.

\section{Problemática em torno dos quadros do $9^{\circ}$ acorde de Delsarte}

\section{Atitudes e matrizes de acordes da nona}

As atitudes do corpo são consideradas por Delsarte como a base da dinâmica. Seu trabaIho é concebido no contexto das matrizes dos acordes de nono, que apresentam um quadro resumindo seu sistema teórico-teológico. Trabalhar as atitudes pode ser considerado como

1 "Aprofundar o Método de François Delsarte: As atitudes do torso e o equilíbrio harmônico." 
a terceira etapa do trabalho somático expressivo, depois da consciência de sua própria verticalidade, depois do relaxamento (decomposição) das diferentes articulações (ver Waille, 2016, capítulo 7).

As atitudes são as disposições ao movimento, como os sentimentos são para Delsarte as disposições ao ato (ver Waille, 2011, p. 79-93). É neste sentido que é possível entender que "a atitude é movimento intrínseco" (Mackaye 1869 / 1870b, p. 129), a manifestação mais imediata de um movimento interior,interior, isto é, de um sentimento. O termo de movimento para falar de atitudes as projeta numa perspectiva dinâmica, que se reflete na pesquisa em fisiologia do movimento: Alain Berthoz indica, após ter apresentada a teoria da sinergia do fisiologista Nikolai Alexandrovich Bernstein (1896-1966), que "o movimento seria, portanto, um deslizamento progressivo de posturas" (Berthoz, 1997, p. 24). Isso também se reflete em duas abordagens contemporâneas de movimento relacionadas à educação somática. Hubert Godard (1995) leva em conta em sua análise do movimento o fundo (que corresponde aqui à atitude), e a figura ou o gesto. Warren Lamb, colaborador de Rudolf von Laban, considera a fusão da postura e do gesto (Posture Gesture Mergers - PGMs): o gesto é apoiado pela postura, a postura apoia a qualidade do gesto (ver Fernandes, 2014, p. 137-138). Em outras palavras, a atitude corresponderia ao pano de fundo de Godard e à base da qualidade da forma para Lamb e Laban. Delsarte analisa o movimento expressivo como estando ancorado na postura, nas atitudes, bases da dinâmica.

As atitudes são, portanto, para ele, as múltiplas posições que diferentes partes do corpo podem assumir em relação a diferentes senti- mentos ou movimentos internos. Sua aparência permanente indica que o corpo, imóvel ou em movimento, está sempre ligado, em seu modo de ser, a um estado interior. Novamente, os elos são possíveis na direção da neurociência, onde existe a noção de "repertório de comportamentos" (Berthoz, 2003. p. 120).

\section{Dinâmica dos quadros dos acordes de nona}

As atitudes deram origem a muitas representações gráficas de Delsarte e de seus alunos sob a forma de "acordes de nona" com referência a todas as partes do corpo. Delsarte retira o termo "acorde de nona" de sua cultura musical, mas lhe dá um sentido completamente novo e próprio aos seus ensinamentos: o acorde de nona em sua obra é uma representação gráfica com finalidade didática, permitindo sintetizar de maneira simples uma realidade complexa. Nenhum dos quadros que Delsarte usava durante suas aulas chegou até nós porque seus documentos pedagógicos hoje em dia estão indisponíveis (ver Waille, 2015a). Existem apenas alguns textos vindos diretamente de suas aulas; alguns descrevem as atitudes, sem nunca serem acompanhados de ilustrações.

$O$ acorde de nona se baseia nos fundamentos teóricos dos ensinamentos delsartianos: a noção teológica de circumincession (relações entre as diferentes pessoas da Trindade), associadas com a definição thomasiana da Trindade (ver Waille, 2011, p. 184-225); é a combinação dos três "dados de base" (em teologia, do Pai, do Filho e do Espírito Santo), que gera nove termos. Cada um desses termos é uma combinação da dinâmica de cada um dos três 
termos originais, que podemos resumir da seguinte forma:

* Pai: 1, dinâmica vital, movimento excêntrico (do centro para a periferia), cor primária vermelha;

* Filho: 2, dinâmica intelectual, movimento concêntrico (da periferia para o centro), cor primária azul;

* Espírito Santo: 3, dinâmica anímica ("da alma" ou sintética), movimento neutro / normal (equilíbrio dos dois anteriores), cor primária amarela.

O acorde de nona geral (a partir das cores primárias) daria isto:

Figura 1: Acorde de nona das cores

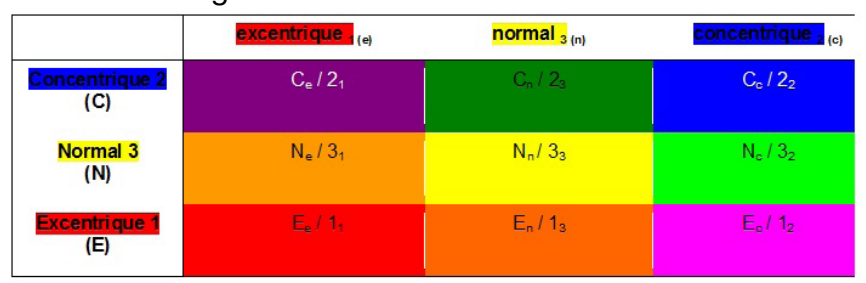

As indicações do tipo emocional acompanham cada atitude do corpo, como por exemplo neste acorde de nona das atitudes dos olhos publicado pelo estudante de Delsarte, o padre Delaumosne:

Figura 2: Acorde de nona das atitudes dos olhos segundo Delaumosne (1874. p. 81).

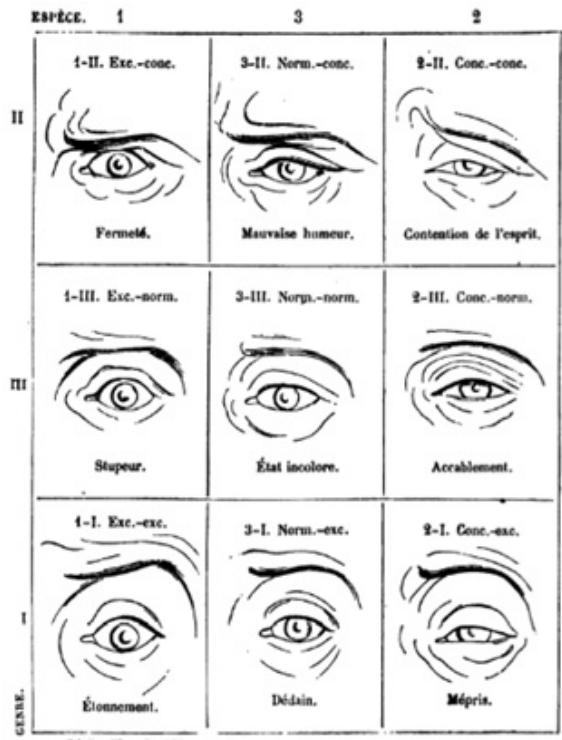

Em documentos de arquivo, estas indicações são sempre plurais (ao contrário do que se encontra na publicação de Delsaumosne) e podem ser acompanhadas da menção "etc." Elas lembram que as atitudes vêm diretamente de observações que encontram um quadro de organização e apresentação dinâmica com o acorde de nona: Delsarte afirma que "esse meio tão simples [lhe permite] registrar os inúmeros fatos que [ele] perseguiu, o que equivale a milhões, [sem se perder] nesses milhões de fatos" (Porte, 1992, p. 121). Além disso, a menção dessas indicações do tipo emocional tem uma dimensão pedagógica: associar um gesto a uma dimensão interna, para que esse gesto seja habitado e não mecânico.

Os acordes de nona são instrumentos que apresentam um processo dinâmico que se processa por subdivisões sucessivas: cada elemento, resultante da passagem de três gêneros para nove espécies, pode ser subdividido por sua vez de acordo com a mesma lógica ternária dentro de um processo sem fim. Esse processo de multiplicação permite a Delsarte refinar sua análise para detalhar os fenômenos expressivos, levando a descrição desses fenômenos para o limite do aplicável. Assim, ele enumerou as combinações que tinha sido capaz de conceber: 729 "fisionomias passionais do mesmo olho" (1859, curso teórico $n^{\circ} 7$ ), sem contar as combinações com os movimentos da cabeça, 6.561 "movimentos" ou "apresentações de mão" (Porte, 1992, p. 142), 42.714 297 "expressões da boca" (Delsarte, 1859, curso teórico $n^{\circ} 7$ ) ... Além disso, ele considera a multiplicação de movimentos potenciais pela combinação dos acordes de nona de diferentes elementos de um conjunto, os braços, por exemplo, ou as combinações entre os acordes de diferentes partes do corpo. Com o acorde 
de nona, ele dispõe de uma grade de leitura dos fenômenos expressivos em direção ao infinito e que ele traz de volta para nove. Não para reduzir tudo a nove, mas para poder trabalhar tudo a partir de nove elementos.

Delsarte está aqui na encruzilhada de dois campos da pesquisa atual em comunicação: os modelos de efeito das emoções (especialmente com a pesquisa de Susana Bloch) e a Nova Comunicação. Os "trabalhos de Paul Ekman e Susana Bloch sobre o fenômeno do feedback psicobiológico em emoções fisicamente estimuladas" (Pradier, 2000, p. 236) tendem a provar que os fenômenos que sustentam uma série de expressões faciais têm um caráter universal. Pode-se ver que, diante de certas expressões faciais, as crianças reconhecem imediatamente essa ou aquela vontade expressiva (raiva, etc.); é sobre isso que atuam a mímica, o circo ou os desenhos animados. Para a Nova Comunicação, é impossível "isolar cada componente do sistema de comunicação global e falar de "linguagem corporal", "linguagem de gestos", etc. (...) [porque] não mais do que enunciados da linguagem verbal, as "mensagens" advindas de outros modos de comunicação não têm significado intrínseco: é apenas no contexto de todos os modos de comunicação, ela mesmo relacionada ao contexto de interação, que a significação pode tomar forma" (Winkin, 2000, p. 24). É preciso, portanto, ao mesmo tempo, considerar uma linguagem do gesto e suas ligações com outras línguas. As variantes e as nuanças possíveis de cada atitude indicada num quadro de acorde de nona, portanto, resguardam três coisas: a possibilidade de refinar cada uma delas de uma maneira quase ilimitada; as ligações com o contexto de comunicação criando interações com outros modos de expressão (inflexões da voz, linguagem articulada); os elos com as diferentes partes do corpo atuando junto no mesmo fenômeno expressivo.

O caráter arquetípico das atitudes na obra de Delsarte encontra eco na tese de Marcel Jousse (1925) em que o antropólogo tomou como "suposição central que toda a atividade do pensamento e da linguagem pode ser reduzida a um conjunto de gestos fundamentais" (Guido, 2007, p. 269), ideia igualmente desenvolvida por Laban (1997. p. 131, \& 2003. p. $161-162,179,204)$. Sua integração por um trabalho repetido, como é o caso na obra de Delsarte, resultaria no estabelecimento de circuitos neurológicos permitindo uma combinação ilimitada que pudesse ser adaptada a qualquer situação emocional e expressiva. Se Delsarte salienta a dimensão psicoafetiva mais do que a pensamento (o faz que Jousse), existe um forte parentesco entre a noção de atitudes arquetípicas que encontramos em Delsarte, e a de movimentos fundamentais defendidos por Jousse.

O quadro do acorde de nona de diferentes partes do corpo formam como um alfabeto corporal cujos elementos podem se agenciar conforme diversas organizações, como os elementos da linguagem escrita se agenciam para formar palavras e depois frases. Estamos na presença de uma combinatória que não é, em Delsarte, unicamente descritiva de uma série de movimentos possíveis, mas que é portadora de sentidos, ou seja, de uma dimensão expressiva. É significativo que Delsarte não proponha aqui, para trabalho corporal, de "léxico emocional" para o conjunto do rosto ou o corpo inteiro, mas fornece informações de treinamento específico para cada elemento expressivo corpo. É um contrasenso imaginar esses quadros de acordes de nona como reper- 
tórios fechados correspondendo de maneira absoluta a uma emoção particular (ver Waille, 2016, Capítulo 3).

\section{Ambiguidades nas transmissões de} atitudes de trabalho

Existem ambiguidades nas transmissões feitas pelos alunos de Delsarte de seu trabaIho de atitudes (tivemos um exemplo em Delaumosne com a falta de pluralidade das emoções associadas a uma atitude), e diferenças significativas na maneira de para apresentar o trabalho. Assim, não existem quadros de acordes de nona em manuscritos de Mackaye mas apenas textos, muito longos, porque apresentam muitas combinações e perdem a dinâmica sintética (ver Waille, 2017). Outros estudantes de Delsarte publicaram quadros de acordes de nona para diferentes partes do corpo (abade Delaumosne - seus quadros foram amplamente reutilizados na América, especialmente por Stebbins - e Alfred Giraudet), que produz ao mesmo tempo um interesse educacional (as figuras substituem longas descrições de exercícios e facilitam o acesso), mas também muitos limites e perigos potenciais.

Com efeito, se Delsarte nunca lançou ou deixou publicar este tipo de quadro em sua vida é porque, por um lado, essas tabelas não têm po função primeira expor uma doutrina estética, mas de ser suporte de treinamento: seu aspecto pedagógico e prático é essencial. $E$ é, por outro lado, sem dúvida alguma porque ele pressentiu o risco inerente a qualquer publicação: o de congelar atitudes em palavras e imagens referentes a emoções.

A publicação pode em virtude disso promover uma leitura errada desses quadros porque fornece uma contribuição puramente intelectual ao seu conteúdo: os desenhos podem aparecer como grades dando diferentes "significações emocionais" das atitudes apresentadas, e não como exercícios como utilizáveis para desenvolver suas capacidades expressivas. Isto é favorecido quando não há pluralidade de situações emocionais potenciais associadas a uma atitude, o que geralmente é o caso em publicações feitas após Delsarte. As placas podem, portanto, ser "lidas" fora de qualquer contexto, sem o qual elas se tornam caricaturas. As publicações dos quadros de acordes de nona têm desempenhado um papel claro nas distorções e má interpretações que às vezes cercam os ensinamentos de Delsarte (veja Waille, 2015b).

É, portanto, adequado conceber esses primeiros quadros como uma série de encadeamentos corporais: "a sequência de movimentos de um mesmo agente pode se fazer quase de todas as maneiras, como uma sequência de notas pode se encadear numa melodia" (Giraudet, 1895. p. 119). Os nove cases de cada quadro são tantas "notas" que devem estar ligadas umas às outras e permitir que os olhos, a boca, os braços ... adquiram uma facilidade expressiva, assim como os dedos do pianista se afrouxam praticando as diferentes escalas musicais. Os quadros são séries de exercícios precisos para cada uma das partes do corpo, e todos os quadros de acorde de nona podem ser vistos como tantos encadeamentos expressivas formando um repertório de treinamento para o artista.

É tendo essas dinâmicas e nuanças em mente que é possível abordar o trabalho das pernas e do tronco como parte no contexto do acorde de nono. 
2. As atitudes das pernas: contribuições combinadas da pesquisa de Clóvis Massa (1991) e Franck Waille (2009 e 2016)

Apresento aqui uma abordagem renovada do trabalho das atitudes das pernas da obra de Delsarte. Acontece que essas atitudes são hoje as mais bem documentadas (ver Waille, 2011 , p. 763-783). No passado, propus duas séries de fotografias dessas atitudes, com base em minhas interpretações de manuscritos de estudantes de Delsarte ou do próprio Delsarte, e desenhos desses últimos. Fiz uma primeira leitura destes documentos em minha tese (2009), lendo que me refinei para os trabaIhos da conferência "François Delsarte. Memória e legados" (ver Waille, 2015d) (informações incluídas em Waille, 2016. p. 339-365).

Eu trago aqui novos elementos sobre a abordagem dessas atitudes, que vêm particularmente das minhas trocas com Clóvis Massa e do encontro com sua pesquisa sobre Delsarte feita na década de 1990. Esta pesquisa, feita por um ator no final de sua formação em Artes Cênicas no Departamento de Arte Dramática da Universidade Federal do Rio Grande do Sul, combinava integralmente teoria e prática. Desde Janis Dawn Clark (1982), é (sem dúvida) o primeiro trabalho relativo a Delsarte associando a análise teórica e a prática expressiva.

O projeto de Graduação (Bacharelado) de Clóvis Massa, defendido em 1991, enfocou o uso de repertórios de signos gestuais no teatro. Massa utilizou elementos de método delsartiano, tais como o treinamento físico e como desenvolvimento técnico no processo de encenação das peças $O$ Canto do Cisne (Tchekov) e Língua de Trapo (inspirado em Grouxo Marx). Este projeto foi concretizado pela realização dessas duas peças e por uma demonstração perante um júri (tudo isso foi filmado), assim como pelo relatório de conclusão de curso intitulado A Significação Corporal A Partir de François Delsarte.

Clóvis Massa utilizou como principal fonte o livro de Stebbins (1977), que apresenta um resumo da transmissão feita por Mackaye, dos livros dos alunos de Delsarte traduzidos para o inglês e do encontro da autora com os alunos de Delsarte em Paris (ver Waille, 2015c). É notável que Massa chegou a inventar um sistema de escritura do encadeamento das diferentes atitudes, sistema de escrita inexistente na literatura que ele consultou, mas que tem fortes parentescos com uma proposição de notação exposta pelo aluno de Delsarte Alfred Giraudet (1895). Isso parece indicar uma forte afinidade pessoal com o trabalho de Delsarte.

A abordagem de Clóvis Massa, através de sua profunda associação da teoria e da prática (o que está em coerência com a dinâmica delsartiana) e por sua inserção no mundo do teatro, veio a complementar minha própria abordagem. Essa foi inspirada pelo mundo da dança e da educação somática. E se ela também aspirava a integrar o sistema (teórico) ao método (prático) de Delsarte (envolvendo uma experimentação pessoal, tornando-se a base de uma transmissão viva desde 2009), ela foi feita, no entanto, num contexto muito diferente, o de um doutorado de história em que a prática era uma opção, uma escolha pedagógica: as ilustrações pela imagem (fotografias e vídeos) foram inicialmente a ajuda para tornar mais acessíveis os textos que descrevem os exercícios. Com a vontade a ir mais perto dos ensinamentos originais, eu expandi ao máximo o alcance de fontes utilizadas, acrescentando aos documentos nos arquivos de Delsarte em 
ambos os lados do Atlântico, as publicações de seus alunos (Delaumosne de 1874 Arnaud, 1882 Giraudet de 1895 Hamel, 1906) e o trabalho de Stebbins (1977), que se refere, bem como documentos de arquivos americanos estudantes Delsarte Steele MacKaye (MFP) e Thomas Stephen Hamel (FH), e Henrietta Hovey (PRH \& TSC), estudante de um filho de Delsarte (Gustave).

A exibição da manifestação de Clóvis Massa diante de seu júri me permitiu identificar imediatamente elementos de expressividade, quer acrescentando dados ao que eu já havia proposto, quer especificando pontos. Em particular, o trabalho de Massa me trouxe dois elementos. Primeiro, me levou a indicar mais claramente a iniciação pelo tórax de certas atitudes (a terceira, e especialmente a quinta, ver infra), em uma dinâmica menos "dançada" e mais próxima da vida cotidiana, o que é absolutamente o espírito do trabalho de atitudes de Delsarte, uma vez que eles vêm diretamente de suas observações da vida cotidiana. Em seguida ele me convidou a ler novamente os textos que descrevem essas atitudes, a fim de destacar a possibilidade, para alguns deles, de fazê-los com os joelhos retos ou dobrados (é o caso de todas as atitudes chamadas normal, isto é, em que o peso é igualmente distribuído em ambos os pés).

Proponho os resultados dessa abordagem combinada de minha própria pesquisa com a de Clóvis Massa pelas fotografias às quais acrescento meus comentários. Eu não devolvo todos os textos e imagens que permitem essas interpretações para não sobrecarregar este artigo, sabendo que esses materiais já foram amplamente apresentados no passado em minhas publicações.
Figura 3: Primeira atitude de base (interpretação pela imagem)

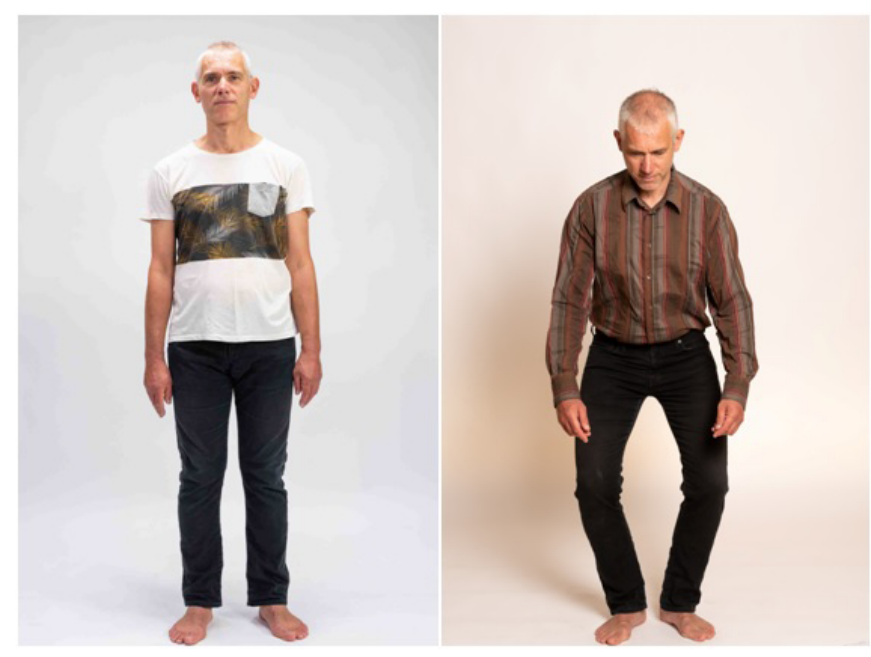

Franck Waille (fotografias @ David VENIER - Universidade Jean Moulin Lyon 3).

Essa atitude "consiste em uma distribuição igual do peso corporal em ambas as pernas" (Mackaye, 1869 / 1870b, p. 1). A dupla posição das pernas é possível na medida em que não há indicação particular sobre este ponto (o que deixa as duas possibilidades em aberto), e que corresponde bem às variedades de expressões que evocam Delsarte. Assim, as pernas estendidas referem-se, antes, à atitude de "o soldado carregando armas - menos a rigidez que afeta uma regularidade desejada por uma disciplina inflexível" ou "aquele que leva o homem na saudação expressando respeito". (ibid.). As pernas dobradas, parecem-me mais relacionadas com "a fraqueza da infância ou da velhice" (ibid.) Ou com a posição "da criança que é colocada pela primeira vez em suas pernas (Delsarte, 1839, p. 24) Esta fotografia de uma menina pequena dá uma boa ilustração do uso desta atitude (em uma versão ligeiramente ampliada) por uma criança (Figura 4): 


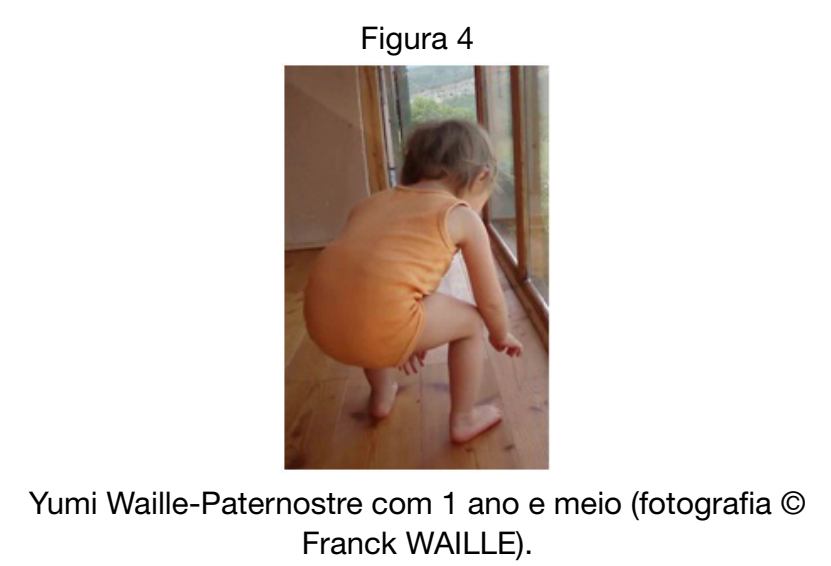

Essa distribuição igual de peso em ambos os pés gera o equilíbrio do corpo bastante estático. Em Delsarte, as posições de equilíbrio nunca são concebidas como paradas absolutas, mas como momentos de deslocamento, que são favorecidos pela posição desbloqueada, livre, "destrancada" dos joelhos (ver Waille, 2016, capítulo 7). O joelho livre permite passar sem quebrar o equilíbrio em duas pernas para um desequilíbrio que será resolvido por um novo equilíbrio, como acontece, por exemplo, quando são encadeadas a primeira e segunda atitudes.

Figura 5: Segunda atitude de base (interpretação pela imagem)

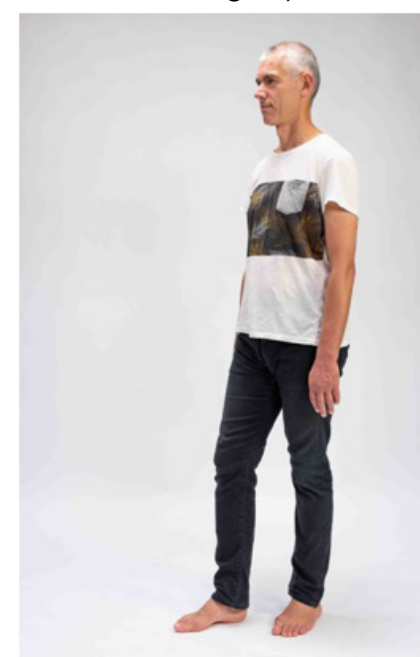

Franck Waille (fotografia @ David VENIER - Universidade Jean Moulin Lyon 3).

A segunda atitude básica é concêntrica: o peso é inteiramente na perna de trás, "ela passa soltando o peso do corpo em um ou outro quadril e trazendo a perna que está livre para a frente (... ) sem tensão ou rigidez" (Mackaye, 1869 / 1870b: 1). Segundo Delsarte, essa atitude caracteriza "descanso em força" (...) "certas paixões concêntricas ocultas sob o lado de fora da calma" (ibid.), "Força, calma, independência" (Delsarte, 1839, p. 24-25). A famosa fotografia de Victor Hugo contemplando o mar na praia de Azette, a perna esquerda esticada e a perna direita relaxada, é uma bela ilustração dessa atitude de descanso observada na vida cotidiana (mesmo que Hugo tranque o joelho de sua perna de apoio). Nós propomos um esquema a lápis (Figura 6):

Figura 3: Victor Hugo na praia de Azette

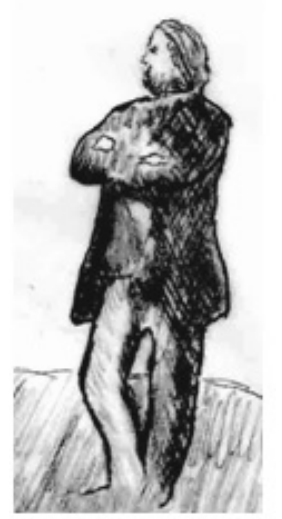

Desenho a partir da fotografia de Charles Hugo (1852@ Franck WAILLE).

A maneira de Delsarte descrever a transição entre a primeira e a segunda atitudes indica a qualidade que ele procura em movimento: "sem tensão ou rigidez". A indicação de "deixar o peso do corpo cair sobre um ou outro quadril" (e não "carregar o peso") reforça a idéia de que é no relaxamento que o movimento é feito. $O$ quadril mencionado aqui (e não a perna) é uma maneira de enfatizar a idéia de um sentimento de descanso associado a essa atitude, porque não é a ação de apoiar o corpo 
(ação da perna de apoio), que é apresentado, mas o de recebê-lo (o peso do corpo repousa, de certa forma, no quadril). Além disso, o foco no quadril e não na perna concentra a atenção no tronco e nas sensações proprioceptivas.

Esta atitude permite fazer uma observação geral durante os deslocamentos induzidos (isto é, a mudança de perna forte) durante o trabalho dessas atitudes, com referência ao relaxamento (decomposição) no movimento. Giraudet de fato transmite que "se a perna livre se retira diretamente (...), o movimento tem constrangimento e peso inevitáveis, porque o pé é plano [na atitude de partida] para retornar plano à atitude [de chegada], há um deslocamento da perna sem desarticulação do tarso e do joelho; daí uma massa pesada e desagradável" (1895, p. 120). É, portanto, uma questão de assegurar o relaxamento das articulações da perna em movimento, em particular ao nível do tornozelo (mas também do joelho). Aqui encontramos as indicações de qualidade ("sem tensão ou rigidez") dadas para a passagem da primeira para a segunda atitude, e a inclusão da decomposição no movimento expressivo como "elemento respiratório".

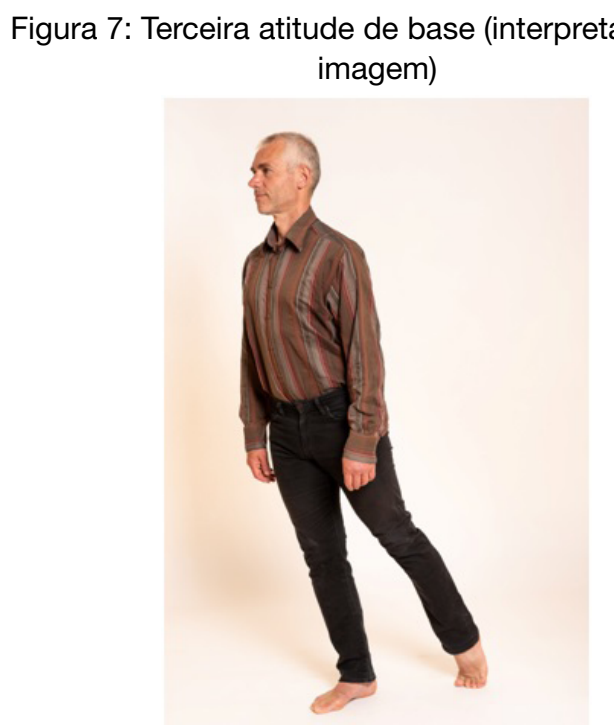

Franck Waille (fotografias (C) David VENIER - Universidade Jean Moulin Lyon 3).
Essa atitude (Figura 7) "consiste em trazer todo o peso do corpo para a frente e esticar a perna traseira em proporções iguais ao grau de avanço do tronco" (Mackaye, 1869 / 1870b, p. 3). Ela "caracteriza a veemência da qual ela é o tipo. É a atitude excêntrica por excelência" (ibid.), "Caracteriza as sensações de raiva" (Van Hymbeck, 1843, capítulo 2).

O texto indica sem ambigüidade qual é o motor do movimento: o torso, que avança. Por torso, é importante entender a parte superior do tronco, isto é, a região do tórax.

De acordo com Delaumosne, essa atitude é particularmente interessante para cantar: "temos uma voz mais forte, pegando seu ponto de apoio (...) na ponta dos pés, tomando a atitude básica que vamos designar (...) sob o termo "terceiro" (1874, p. 19) ele escreve. Deve-se acrescentar que as oposições no corpo (por exemplo, uma oposição contralateral associada à terceira atitude das pernas) reforçam essa sede corporal da voz. É possível fazer a observação dizendo ou cantando a mesma frase em diferentes atitudes e organizações do instrumento do corpo, e observar as modificações induzidas em termos de qualidade e potência da emissão. Note que o poder vocal em questão aqui não tem nada a ver com poder forçado, é um poder apoiado pelo organismo e sua organização. 
Figura 8: Quarta atitude básica (interpretação pela imagem)

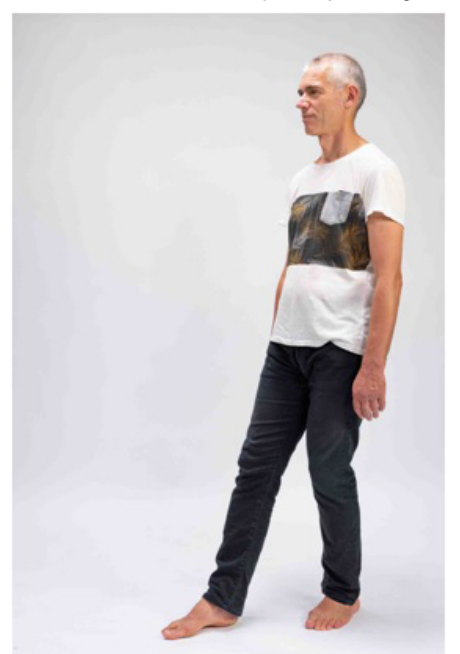

Franck Waille (fotografias ( David VENIER - Universidade Jean Moulin Lyon 3).

Essa atitude consiste em carregar todo o peso do corpo para trás, ao contrário da atitude anterior em que o corpo é levado adiante, e dobrar a perna que recebe o peso do corpo ao contrário do outro que deve ser esticado (...) Podemos, além disso, verificar a regularidade dessa atitude pelo ajoeIhar que é o paroxismo: se é bem feito, facilmente leva a isso (Mackaye, 1869/ 1870b, p. 3).

Ela "caracteriza a fraqueza que sucede a veemência, é o tipo de concentração, é também em seu caráter como em seu aspecto o antípoda do terceiro, já que é sua expressão reativa" (Mackaye, 1869/1870b, p. 3) (Figura 8); em outras palavras, está associado ao "desânimo resultante da veemência espontânea dos movimentos excêntricos". A fraqueza natural manifesta-se em $1^{\mathrm{a}}$, a fraqueza súbita em $4^{\circ}$ (Delsarte, 1839, p. 25).
Figura 9: Quinta atitude básica (interpretação pela imagem)

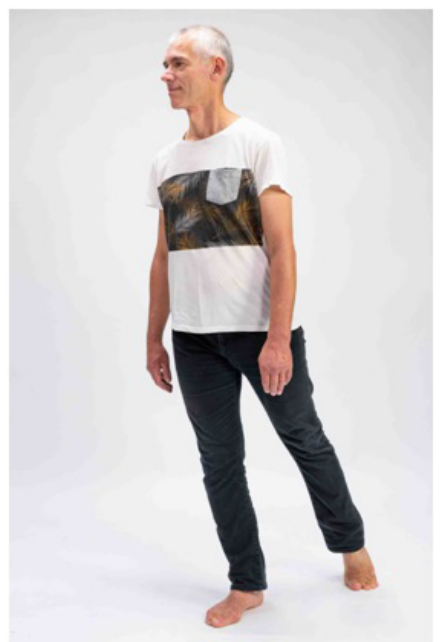

Franck Waille (fotografias (C David VENIER - Universidade Jean Moulin Lyon 3).

Essa atitude (Figura 9) "é necessária pela inclinação do tronco de um lado ou do outro. É uma espécie de terceira. É uma das atitudes mais importantes na extensão: é a atitude transitiva ou passageira, que completa todos os ângulos operados pela marcha" (Delsarte, 1839 , p. 25). Serve como uma preparação para marchas oblíquas, também é incolor, transitiva, suspensiva, termina nos passos todos os cantos dos ângulos" (Mackaye, 1869 / 1870b, p. 3).

Delsarte insiste em iniciar o movimento pelo torso, o que provoca o movimento de adaptação das pernas para o lado. Esta atitude é essencialmente dinâmica - daí a sua aparência excêntrica - porque associada aos passos em diagonal: Laban (2003, p. 169) indica que a diagonal é a linha mais móvel (ao passo que se formos apenas para o lado, há pouca mobilidade). Na transmissão feita por Mackaye, essa atitude perde seu aspecto dinâmico, pois não está associada à caminhada na diagonal (1886. p. 52); ela possui então um caráter estático. Essa perda de energia é ainda mais prejudicial porque Delsarte afirma em relação à quinta ati- 
tude que "é depois da segunda, a atitude cujo uso é mais frequente" (1839, p. 25).

Na minha versão de 2009, minha compreensão do conceito de "inclinar o tronco" era um pouco reta:

Figura 10: Versão antiga da $5^{\mathrm{a}}$ atitude das pernas (2009)

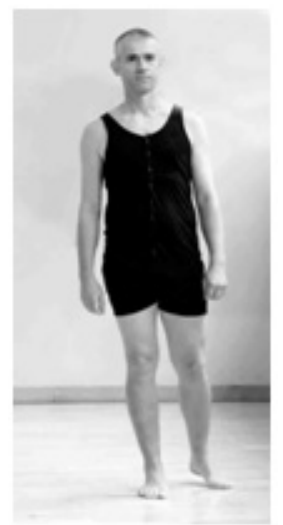

Franck Waille (fotografias @ David VENIER - Universidade Jean Moulin Lyon 3).

A versão que Clóvis Massa dá no filme que eu vi parece muito mais precisa: a inclinação do torso vista como uma orientação do tronco em uma direção - e o torso sendo o elemento condutor, ele então se inclina um pouco. nessa direção, para treinar o resto do corpo.

Figura 11: Sexta atitude básica (interpretação pela imagem)

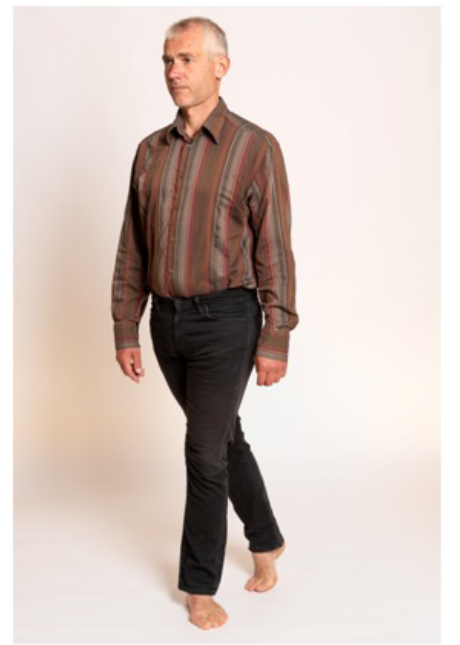

Franck Waille (fotografias @ David VENIER - Universidade Jean Moulin Lyon 3).

"A $6^{\mathrm{a}}$ determina passos oblíquas, é uma es- pécie de terceiro inversa" (Delsarte, 1839, p. 25), (Figura 11) "a ponta do pé da frente deve ser muito fora para manter o equilíbrio, tem, para se verificar a exatidão desta posição, que levantar a perna de trás" (Van Hymbeck, 1843, capítulo 2): "a perna livre da quinta tornase (em pé lateralmente e ligeiramente para a frente e fortemente para dentro) a perna forte e opera por isso um cruzamento com a perna traseira" (Mackaye, 1869 / 1870b, p. 3).

Isto é provavelmente porque é definida como "uma atitude de pompa, cerimônia" (ibid.) Que foi acusada de ter "algo incompreensível" por Giraudet (1895, p. 87, nota 2), para quem a ideia de respeito e reverência "não pode acomodar atitudes": "Esta forma de saudação pomposa só poderia entrar na dinâmica, e ainda não tem caráter típico" (id., p. 87) ele acrescenta. Giraudet assumiu a responsabilidade por uma mudança, assim como Mackaye e depois os delsartistas americanos. Mackaye substitui de fato essa atitude por uma variante da terceira atitude com a forte perna dobrada (ele chama a $8^{\mathrm{a}}$ atitude dos pés). Aqui está uma ilustração (Figura 12), publicada pela Stebbins:

Figura 12: Atitude "excêntrico-excêntrica" das pernas de acordo com Stebbins (1977, p. 153).

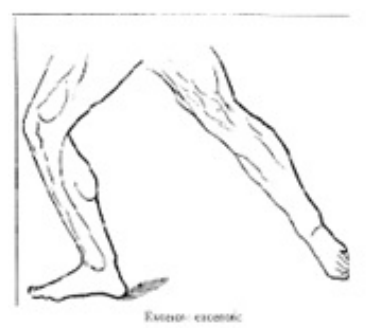

Em um texto que descreve a nona atitude, Delsarte refere-se a "quarta que é a única atitude cuja perna forte é flexionada" (Mackaye 1869 / 1870b, p. 4): a versão americana está em flagrante contradição com a declaração Delsarte. 
Hamel dá a chave para explicar a sexta atitude básica:

Finalmente, a forma normal do tipo excêntrico (...) é que a perna forte está ligeiramente à frente da perna fraca. É uma posição puramente transitória que expressa curiosidade e ansiedade e que é prontamente resolvida em uma mais estável. Assim, Delsarte, partindo de seu rigor teórico, substituiu-o por outro que é mais um passo reverencial do que uma atitude (1906, p. 155-156).

Essa atitude é essencialmente transitiva e dinâmica, permite a passagem de uma atitude para outra. É significativo que Delsarte inclua especificamente atitudes "transitivas" ou "passageiras" em atitudes básicas. Isso ilustra seu lugar central em movimento (aqui entendido como movimento no espaço) de um ponto de vista prático (assim como teórico, ver Waille, 2016, capítulo 3). Assim, o movimento tem um "caráter típico" para Delsarte, representado pela $5^{\mathrm{a}}$ e $6^{\mathrm{a}}$ atitudes.

Nas transmissões americanas, é significativo que as duas atitudes transicionais (5a e 6a) foram suprimidas ou modificadas em um sentido estático. De modo mais geral, se Mackaye mostra a organização geral em nove atitudes de pernas (que ele chama de "expressões pés com equilíbrio harmônico" ["expression of feet with harmonia poise" (1886, $8^{\mathrm{a}}$ aula)]), ele suprime uma, introduzindo uma nova, modifica parcialmente outras e troca a maior parte de suas numerações (ver Waille, 2016, p. 359, nota 272): ele apresenta num primeiro momento três atitudes normais e três atitudes concêntricos e, finalmente, três atitudes excêntricas (ele não usa esse vocabulário, que acabou excluindo de seu ensino - ver Waille, 2017). Sua classificação mostra que sua prioridade não é a sequência de atitudes como em Delsarte, mas o estabelecimento de uma série de posições estáticas. Há, então, uma lacuna com a abordagem original estabelecendo uma ligação com as observações da vida cotidiana e o trabalho expressivo. Isto, juntamente com a exclusão do aspecto dinâmico ligado à $5^{a}$ posição e a eliminação da $6^{\mathrm{a}}$ atitude, convida a pensar que as alterações feitas por Mackaye sobre as atitudes pernas podem em grande parte explicar o "sistema de Delsarte -Mackaye" (Ruyter 1991, p. 35) foi percebida na América como essencialmente estática, e às vezes ele derivou práticas puramente de ginástica, duas características alheias ao trabalho do próprio Delsarte. E se Stebbins - que segue entretanto o essencial das atitudes de pernas feitas por Mackaye - se supõe ter "acrescentada a dinâmica às evoluções essencialmente estáticas do sistema Delsarte-Mackaye" (ibid.), é preciso compreender isso no contexto do delsartismo e não no ensino do próprio Delsarte. Esse é precisamente orientado para a dinâmica de uma maneira geral, e sobre este ponto particular do trabalho das atitudes das pernas. A dinâmica está no coração da arte e da pedagogia que Delsarte defende (ver Waille, 2011).

Figura 13: Sétima atitude básica (interpretação pela imagem)

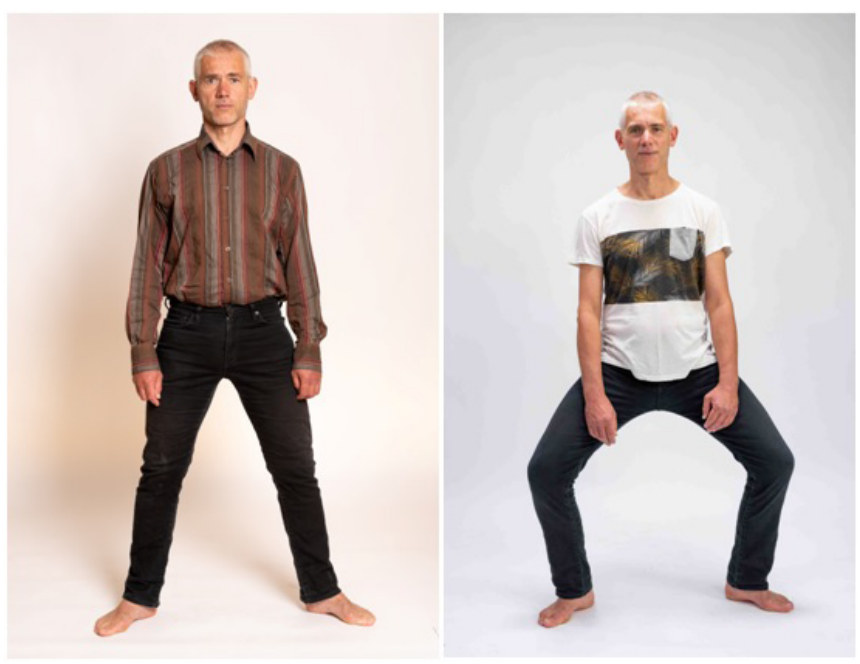

Franck Waille (fotografias (C David VENIER - Universidade Jean Moulin Lyon 3). 
"Essa atitude é simplesmente um primeiro esclarecimento, e por isso deve ter grandes afinidades morais com essa atitude. Esta atitude consiste na distribuição do peso do corpo em ambas as pernas paralelas e amplamente separadas" (Mackaye, 1869/1870b, p. 3-4). (Figura 13) Quanto à primeira, existe a possibilidade de ter os joelhos retos ou dobrados (como por exemplo nas artes marciais orientais). É designada por Delsarte como aquela de "repouso absoluto" (1859, corte prática $n^{\circ}$ 8); garante uma grande estabilidade; "caracteriza a pessoa responsável, isto é, a atitude mais forte, e consequentemente aquilo que a embriaguez toma para resistir à falta de desenvoltura. É a mesma que a de um homem mortalmente atingido, em uma palavra, a atitude de vertigem ou extrema confiança. Não nos surpreendamos, então, com a abordagem desses diferentes e opostos termos nessa atitude, pois será suficiente para nós entendermos esse princípio - que uma atitude forte é buscada pela fraqueza, pois a atitude fraca é afetada pela força. (Mackaye, 1869/1870b, p. 3-4).

Lembre-se, no que diz respeito ao conceito de joelhos direitos, é fundamental para Delsarte garantir que os joelhos estejam sempre relaxados, isto é, que estejam sempre desbloqueados, ou seja, sempre potencialmente adequados para a mobilidade. no espaço. Os joelhos estão retos sem estarem bloqueados.
Figura 14: Oitava atitude básica (interpretação pela imagem)

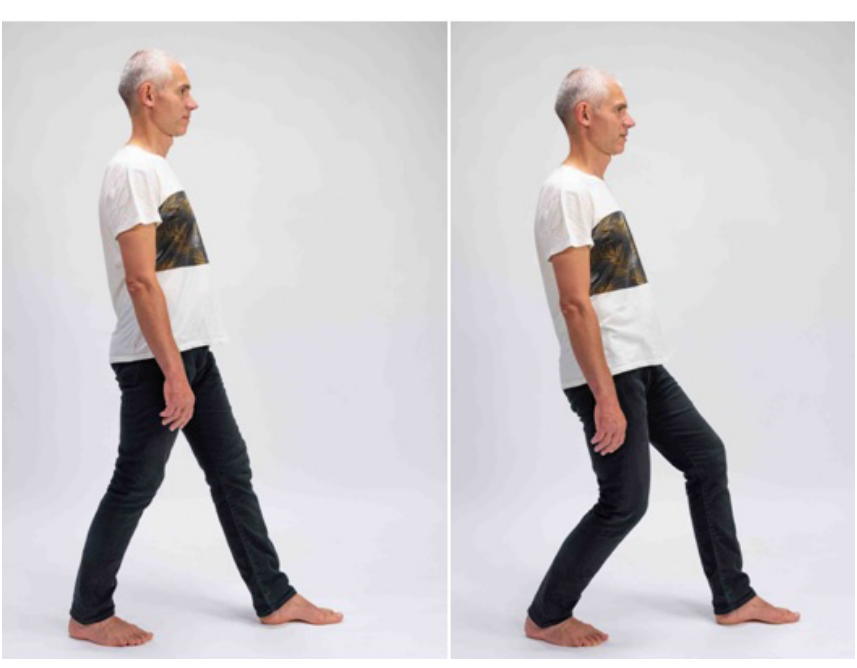

Franck Waille (fotografias @ David VENIER - Universidade Jean Moulin Lyon 3).

Esta é a última atitude normal (peso repartido nas duas pernas). (Figura 14) "A partir da sétimo, deve-se pelo movimento do lado do torso fazer girar sobre a ponta dos pés sem movê-los de lugar, de modo a ter os dois pés paralelos à posição do corpo" (Van Hymbeck, 1843, capítulo 2). ). Delsarte se refere a ela como "uma atitude de parada, (...) igualmente ofensiva e defensiva" (ibid.); "Ela serve para a excentricidade com relutância, para a ameaça, para o ciúmes" (Delsarte, 1839, p. 25); "É o meio exato entre a terceira e a quarto, então expressa a alternativa, tanto moral quanto física, entre essas duas atitudes. O homem colocado entre a defensiva e a ofensiva sempre toma essa atitude alternativa para sondar os recursos de sua coragem na presença de um inimigo mais forte que ele, podendo alternativamente nesta atitude avançar ou recuar" (Mackaye, 1869 / 1870b, p. 4).

Como outras atitudes normais, ela pode ser feita com os joelhos retos ou flexionados. Vendo o filme de demonstração de Clóvis Massa, eu achei que a versão com os joelhos flexionados era particularmente reveladora, por exemplo, no contexto de uma pessoa na defensiva / 
ofensiva chegando a um local potencialmente ameaçador (se colocando em guarda e apontando sua arma, por exemplo, ou se preparando para se mover em qualquer direção, ou na posição de defesa em uma arte marcial). Eu tentei oferecer uma ilustração fotográfica da seguinte forma:

Figura 15: Possíveis variações da $8^{a}$ atitude das pernas (pernas dobradas) incluindo os braços

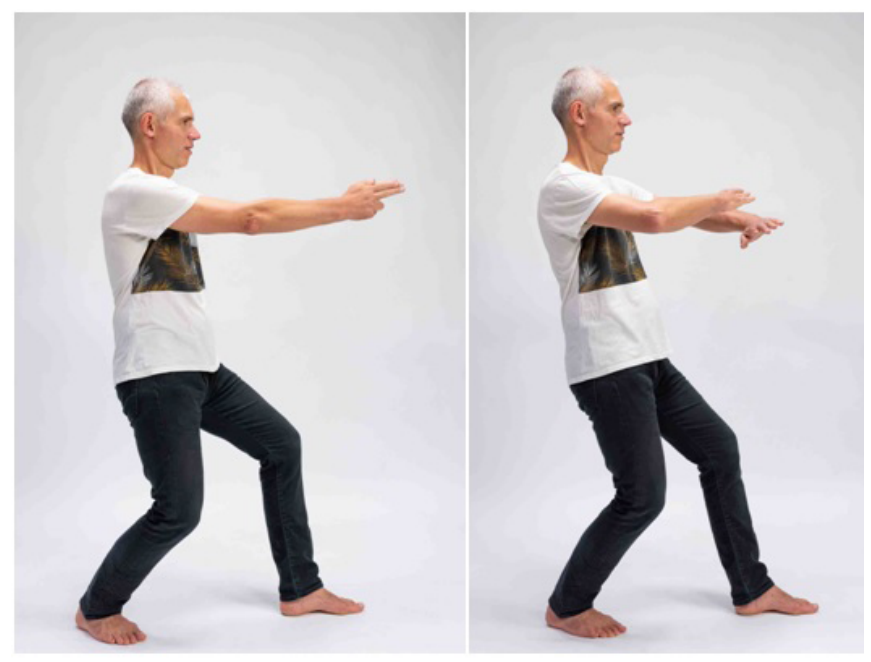

Franck Waille (fotografias ( David VENIER - Universidade Jean Moulin Lyon 3).

Nas descrições desta atitude (Figura 15), o tronco ainda é muito claramente designado como a força motriz por excelência. De fato, seria possível passar da sétima para a oitava atitude por meio de um giro das pernas ou por um movimento da pélvis, mas o manuscrito especifica que é "por um movimento lateral do tronco" que os pés e o corpo como um todo, mudará de posição.

Além disso, Delsarte dá uma indicação dinâmica mostrando como é possível fazer um exercício a partir desta oitava atitude: "se quebrarmos estaremos em 4a, se avançarmos estaremos em 3a" (Van Hymbeck, 1843, capítulo 2). Em outras palavras, ele propõe experimentar, pernas espalhadas em uma linha de frente/ trás, a passagem de uma distribuição igual de peso nas duas pernas (oitava atitude), a essa do peso sobre a perna de trás (quarta atitude) depois sobre a perna da frente (terceira atitude). $\mathrm{O}$ interesse deste exercício é sentir, a partir de uma posição equilibrada, a progressiva transferência do peso sobre a perna que é avançado ou o que é retraído, isto é, para trabalhar de uma maneira excelente a propriocepção. consciente, em conexão com a sensação de peso. Este tipo de trabalho pode ser encontrado hoje em uma aula de dança contemporânea, com muitas variações.

Figura 16: Nona atitude básica (interpretação pela imagem)

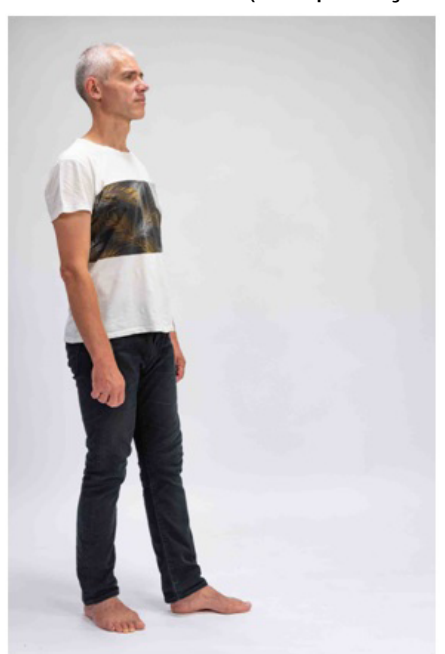

Franck Waille (fotografias () David VENIER - Universidade Jean Moulin Lyon 3).

"Essa atitude é uma segunda estendida, difere apenas no sentido de que a perna livre está estendida em vez de estar flexionada, como na segunda. (...) É necessário (...) que o corpo se coloque com força no quadril da perna forte para que o lado da perna livre possa se alongar" (Mackaye, 1869/1870b, p. 4). (Figura 16) "Caracteriza o desafio" (id.). É "uma atitude de parada; ela é quase simultaneamente ofensiva e defensiva. Sua aparência impressiona facilmente, ele lança o ouvinte na alternativa. $\mathrm{O}$ que vai acontecer? que sentimento virá dessa atitude que deve ter sua resolução tanto no ter- 
ceiro quanto no quarto (Delsarte, 1839, p. 25).

Esta última indicação insiste no caráter dinâmico dessa atitude, que deve encontrar uma solução excêntrica ( $3^{a}$ atitude) ou muito concêntrica ( $4^{\mathrm{a}}$ atitude). Simbolicamente, esta tendência da nona atitude de ser resolvida em outra atitude ecoa a dinâmica do número 9: fim do ciclo básico (de 1 a 9), abrindo no próximo ciclo (10, ou retorno à unidade). 1) (ver Chevalier, Gheerbrant, 1982, p. 663-665).

Delsarte propõe, como Giraudet especifica, treinar-se para encadear as várias atitudes do corpo "em todos os sentidos" (1895, p. 119), isto é, em qualquer ordem. Para as nove atitudes pernas, os manuscritos dão indicações para as encadear da primeira à nona, ou então de as encadear por grupos de três (os normais, os excêntricos e os concêntricos). De qualquer forma, é claro que é tanto cada uma das atitudes nelas mesmas que importa para Delsarte que o movimento de sua sequência: estamos constantemente na passagem da estática para a dinâmica.

Acrescentemos que Giraudet é o único estudante de Delsarte a apresentar três grandes tipos de atitudes das pernas: o tipo excêntrico, quando a pessoa está de pé; o tipo concêntrico, quando a pessoa está ajoelhada ou tem uma nádega no chão; e o tipo normal quando a pessoa se senta (em um suporte, não diretamente no chão) (1895, p. 87-93).

\section{Conclusão}

As atitudes das pernas ou "atitudes de base" (Cable, s.d., p. 1) são exatamente as bases da dinâmica: elas são a base da organização corporal geral. As outras atitudes que tem uma incidência direta na organização global do corpo são as as do torso. Elas tem uma ligação direta com a noção de equilíbrio harmônico característico das transmissões delsartianas. Eu apresentarei esses elementos num segundo artigo a ser apresentado na sequência desse.

É importante repetir (como nas minhas publicações de 2011 e 2016) que as fotografias são o meu entendimento e parte do meu comentário sobre as informações coletadas. Elas não têm caráter normativo nem pretensão estética. Eles são, por natureza, susceptíveis de evoluir, e este é o motivo principal deste artigo: propor uma atualização de possíveis interpretações de documentos, atualização que também é susceptível de evoluir. As fotografias aqui apresentadas foram feitas especialmente para este artigo e apresentam diferenças notáveis em relação a outras publicadas anteriormente sobre o mesmo tema, como vimos um exemplo. Além disso, a variedade de informações transmitidas por diferentes alunos e / ou documentos certamente se refere às diferentes variações e nuances que Delsarte introduziu em seu ensino, variações que convidam a essa dinâmica aberta e constantemente suscetíveis a novas interpretações. O encontro com a abordagem de Clóvis Massa destacou a riqueza desta variedade de interpretações possíveis.

As fotografias aqui apresentadas pretendem ser nada mais que meras ilustrações de uma interpretação, num dado momento da minha pesquisa, das propostas de formação a que se referem. Meios visuais de textos, eles têm muitas imperfeições que o leitor me perdoará ... e que ele terá, espero, o bom-senso de esquecer ao se envolver na prática dos exercícios expostos. Se este artigo lhe der o desejo, ele terá alcançado seu objetivo! 


\section{Abreviaturas}

DC [= Coleção Delsarte]: "Documentos de François Alexandre Nicolas Delsarte, Mss. 1301, Louisiana e Lower Mississippi Valley Coleções, bibliotecas LSU, Baton Rouge, The."

FH: Hamel fonds, Fundos dos arquivos do Séminaire de Québec: SME (1626-1994), Museu da civilização, Coleções, Arquivos Históricos e Serviço de Bibliotecas, Quebec, Quebec, Canadá.

MPF: Os papéis da Família Mackaye, Biblioteca Baker, Coleções Especiais, Dartmouth College, Hanover, New Hampshire, EUA (Manuscrito ML-5, Série 7, Steele MacKaye, 18481916, caixa de $7 \& 8$ / Manuscrito ML-5, Series 22, Addendum 1, box 219).

PRH: Os Documentos de Richard Hovey, Biblioteca Baker, Coleções Especiais, Dartmouth College, Hanover, New Hampshire, EUA.

TSC: Coleção Ted Shawn, Lincoln Center, Divisão de Dança Jerome Robbins, Biblioteca Pública de Nova York para as Artes Cênicas, Nova York, EUA, Classificação: (S) * MGZMCRes. 31, série VIII "Sistema Delsarte de Expressão".

Bibliografia e fontes (impressas ou manuscritas)

ALEXANDER, Frederick Mathias. O Uso do Eu. Bruxelas: Edições Contredescas [O Uso do Ser], 1996 [1923].
ARISTOTE. Animal Walking. Movimentos de animais. Índice de tratados biológicos. Paris: Les Belles Lettres, 1973.

ARNAUD, Angélique. François del Sarte, suas descobertas em estética, a sua ciência, seu método, precedido por detalhes de sua vida, sua familia, seus relacionamentos, seu personagem. Paris: Ch. Delagrave, 1882.

BAINBRIDGECOHEN, Bonnie. Sentir, sentir e agir. A anatomia experimental do Body-Mind Centering ${ }^{\circledR}$ (tradução de Sensing, feeling and action, par Madie Boucon). Bruxelas: Dance News $\mathrm{n}^{\circ}$ 50, 2002.

BARBA, Eugenio. SAVARESE, Nicola. A energia que dança. Dicionário de Antropologia Teatral. Montpellier: L'Entretemps, 2008.

BARTHÉLÉMY, Yva. A voz liberada. Paris: Robert Laffont, 1984.

BERTHOZ, Alain. O significado do movimento. Paris: Odile Jacob, 1997.

BERTHOZ, Alain. A decisão. Paris: Odile Jacob, 2003.

CABO. Caderno de Cabo enquanto estuda com Delsarte [Caderno do Cabo Estudantil com Delsarte] (DC, caixa 2c, pasta 132). (s.d.).

CHEVALIER, Jean; GHEERBRANT, Alain. Dicionário de símbolos. Paris: Bouquins, Robert Laffont / Jupiter, 1982. 
DAWN CLARK, Janis. A Influência do Sistema de Expressão de Delsart no American Acting 18711970. Ph.D. Dissertação, Washington State University, 1982.

DELAUMOSNE, Abbé. Prática da arte oratória de Delsarte. Paris: Joseph Albanel, 1874.

DELSARTE, François. Escola de Delsarte, Escola de canto moral e científico. Notas e relatório de suas palestras, 1839 (DC, caixa 11b, pasta sem \#). Transcritores diferentes, com anotações e assinatura de Delsarte. 1839.

DELSARTE, François. Curso de $M$. Delsarte às sociedades eruditas, curso $\mathrm{n}^{\circ} 8$ (DC, caixa $12 \mathrm{~b}$, pasta 54), 1858.

DELSARTE, François. Estética aplicada, curso de F. Delsarte. Exposição em nove lições da arte do orador, do pintor e do músico. Oferecido ao Sr. Delsarte por seu aluno Alphonse Pages (DC, caixa 12c, pasta 40),1859.

DELSARTE, François. Beau (DC, caixa 9-10, pasta OS 36a, documento 3), (s.d.).

FERNANDES, Ciane. The Moving Researcher: Análise do Movimento Laban/Bartenieff em Educação em Artes Cênicas e Terapias de Artes Criativas. Kingsley: Jessica Publisher, 2014.

GIRAUDET, Alfred. Mimetismo, Fisionomia e Gestos. Método Prático De acordo com o sistema de François Del Sarte para servir a expressão dos sentimentos. Paris: Ancienne Maison Quantin/Librairies-Imprimeries Réunies, 1895.
GODARD, Hubert. "Le geste et sa perception." In: GINOT, Isabelle; MICHEL, Marcelle. (Org.). La Danse au XX Siècle. Paris: Bordas, 1995, p. 224229.

GUIDO, Laurent. A Era do Ritmo - Cinema, Musicalidade e Cultura Corporal em Teorias Francesas dos Anos 1910-1930. Lausanne: Éditions Payot/Jacques Scherrer éditeur, 2007.

HAMEL, Thomas-Étienne. Curso de eloquência falado depois de Delsarte. Quebec: Imprimerie da companhia do Evento, 1906.

JOUSSE, Marcel. Estudo da psicologia lingüística. O estilo oral rítmico e mnemônico dos verbomotores. Paris: Beauchesne, 1925.

LABAN, Rudolf. O domínio do movimento. Arles: Actes sud, 1997.

MACKAYE, James Steele. Caderno de Mackaye enquanto estudava com Delsarte $n^{\circ}$ 3/7 [Caderno estudante Mackaye com Delsarte $n^{\circ}$. 3/7] (CD, caixa 12b, pasta 7), 1869/1870a.

MACKAYE, James Steele. Caderno de Mackaye enquanto estudava com Delsarte $\mathrm{n}^{\circ} 12$ [caderno de estudantes de Mackaye com Delsarte $\left.n^{\circ} 12\right]$ (CD, faixa 35), 1869/1870b.

MACKAYE, James Steele. Harmonic Gymnastics (DC, caixa 6, pasta 76), 1886.

MASSA, Clóvis Dias. A significação corporal a partir de François Delsarte. Projeto de Graduação, ligado à FAPERGS através da pesquisa teórica "Emprego de Signos Gestuais", Departamento de Arte Dramática da Universidade Federal do Rio Grande do Sul (UFRGS), Porto Alegre, 1991. 
PORTE, Alain. François Delsarte, uma antologia. Paris: IPMC. 1992.

PRADIER, Jean-Marie. A cena e a fábrica de corpos. Etnocenologia das artes cênicas no Ocidente. Século V a.C.-XVIII. Talence: Presses Universitaires de Bordeau, 2000.

RUYTER, Nancy Lee Chalfa. Delsarte, seu sistema e os Estados Unidos, em François Delsarte, 1811-1871. Fontes-Pensamento, Châteauvallon: Teatro Nacional de Dança e Imagem, p. 33-37, 1991.

SMALLS, James. Homossexualidade em Arte. New York: Parkstone Press, 2003.

STEBBINS, Genevieve. Delsarte Sistema de Expressão. New York: Dance Horizons (reedição da $6^{a}$ edição [1902] do livro de Stebbins, originalmente intitulado Sistema Delsarte de Expressão Dramática, publicado pela primeira vez em 1885), 1977.

VAN HYMBECK, Auguste. Resumo das aulas de canto, gramática, atitudes, etc. A palestra do Sr. Delsarte, caderno de estudantes Van Hymbeck com Delsarte (DC, caixa 8, pasta 9, documento 2), 1843.

WAILLE, Franck. Corpo, artes e espiritualidade em François Delsarte (1811-1871). Interações dinâmicas. Lille, ANRT (viva [2009] versão online, capítulo por capítulo, em https://scdresnum.univ-lyon3.fr/out/theses/2009_out_waille_f.pdf), 2011.

WAILLE, Franck. Os arquivos de François Delsarte, fontes e produto de um trabalho científico, em Waille, Damour (2015): 19-22, $2015 a$.
WAILLE, Franck. "Encontrar a vitalidade dos ensinamentos de Delsarte: expressiva (ou estereotipado nem fisionômica) e inscrito no movimento (não congelado)", em Waille, Damour (2015) : 77-94, 2015b.

WAILLE, Franck. "Alfred Giraudet, artista lírico e pedagogo delsartiano", em Waille, Damour (2015) : 113-126, 2015c.

WAILLE, Franck. "A Expressiva Corporal de Delsarte: Das Observações Diárias ao Treinamento Corporal Estruturado", em Waille, Damour (2015) : 273-280, 2015d.

WAILLE, Franck. O expressivo método somático de François Delsarte. Histórica, estética, antropológica: da neurofisiológica à metafísica. Montpellier: L'Entretemps, 2016.

WAILLE, Franck. "François Delsarte e as artes cênicas: The American Survey", postado no site da Acfas (French Language Association), junho de 2017 (http://www.acfas.ca/publica-tions/decouvrir/2017/06/francois-delsarte-arts-scene-enquete-americaine), 2017.

WAILLE, Franck, DAMOUR, Christophe (dir.) François Delsarte, uma busca sem fim. Paris: L'Harmattan, 2015.

WINKIN, Yves. A Nova Comunicação. Paris: Seuil, 2000.

(Eu traduzi para o francês os textos vindos do inglês).

Tradução de Clóvis D. Massa. 
Recebido: 19/12/2018

Aprovado: 11/01/2019 